\title{
A LEI NATURAL COMO VONTADE DE POTÊNCIA. CONSIDERAÇÕES NIETZSCHIANAS ACERCA DA LEGISLAÇÃO DA NATUREZA
}

\author{
Adilson Felicio Feiler ${ }^{1}$ \\ Universidade do Vale do Rio dos Sinos (UNISINOS) \\ (i) https://orcid.org/0000-0001-7352-927X \\ E-mail: afeiler@unisinos.br
}

\section{RESUMO:}

A presente investigação se empenha em mostrar as considerações de Nietzsche acerca da lei natural. Dado que o filósofo alemão baseia o seu pensamento em uma concepção organicista, em princípio se é levado a pensar em uma acolhida e até ênfase positiva quanto a lei natural. No entanto, em diversas passagens de seus escritos Nietzsche se mostra hostil quanto a lei natural, por principalmente atuar como enquadramento, medição e cálculo do movimento da natureza. A lei natural, por essa razão, consiste em falsificação da natureza. Pois, os mecanismos legais se impõem sobre o livre atuar da natureza, destituindo-a de sua singularidade orgânica para enquadrá-la numa racionalidade artificial. O livre atuar da natureza não pode ser capturado por mecanismos de enquadramento racional ditados pela lei natural. Contudo, Nietzsche reconhece na vontade de potência uma espécie de lei natural que atua sobre os fenômenos naturais sem os constranger, mas os conduz até os mais altos cumes da força.

PALAVRAS-CHAVE: Nietzsche; Lei natural; Vontade de potência; Força.

\section{THE NATURAL LAW AS WILL TO POWER. NETZSCHIAN'S CONSIDERATIONS ABOUT NATURE LEGISLATION}

\begin{abstract}
:
The present investigation strives to show Nietzsche's considerations about natural law. Since the German philosopher bases his thinking on an organicist conception, in principle one is led to think of a welcome and even a positive emphasis on natural law. However, in several passages of his writings Nietzsche is hostile towards natural law, mainly because it acts as a framework, measurement and calculation of the movement of nature. Natural law, for this reason, consists in falsifying nature. For, the legal mechanisms are imposed on the free action of nature, depriving it of its organic singularity to fit it in an artificial rationality. The free action of nature cannot be captured by rational framing mechanisms dictated by natural law. However, Nietzsche recognizes in the will to power a kind of natural law that acts on natural phenomena without constraining them, but leads them to the highest peaks of force.
\end{abstract}

KEYWORD: Nietzsche; Natural Law; Will to Power; Strength.

\footnotetext{
${ }^{1}$ Doutor(a) em Filosofia pela Pontifícia Universidade Católica do Rio Grande do Sul (PUCRS), Porto Alegre - RS, Brasil. Professor(a) da Universidade do Vale do Rio dos Sinos (UNISINOS), São Leopoldo - RS, Brasil.
}

FEILER, Adilson Felicio. A lei natural como vontade de potência: considerações nietzschianas acerca da legislação da natureza. Griot : Revista de Filosofia, Amargosa - BA, v.21 n.3, p.375-389, outubro, 2021. 


\section{Introdução}

Nietzsche possui uma concepção de vida que se afirma sob a dinâmica das forças. Neste sentido, todos os fenômenos naturais atuam para fortalecer a vida a fim de capacitá-la ao enfrentamento de embates que se impõem. Assim, quanto mais fortes forem os embates, tanto mais força se despenderá a ultrapassá-los; e, neste vai e vem de obstáculos e superações a vida vai se configurado como vontade de potência, como vontade de assenhoramento. Este fenômeno, caracterizado pelas forças, perpassa a vida como um todo, desde os seres inanimados, as pedras, a água, o fogo, passando pelas plantas, os animais até atingir o animal homem. $O$ ser humano, mediante a abertura de seus poros, portanto, fiel à terra, absorve as forças que perpassam o mundo em todas as suas dimensões. Estas forças, ao perpassarem os tecidos humanos, potenciam o seu hospedeiro a uma descarga que se expressa como vontade de potência, mediante a expressão do criar. Como criador, o homem é capaz de ultrapassar os limites que se interpõem no sentido de alçar sempre patamares mais culminantes de força. E a cada patamar culminante da força que se atinge, um instante de plenitude se vive. No entanto, cada instante de força não passa de apenas um instante, por isso, dá lugar a outro instante, e, assim, sucessivamente, num combate anímico incessante composto de pontos de força disposto hierarquicamente. Nesta hierarquia nada está fixo, mas seguindo a dinâmica das forças, em seu devir incessante, se atinge níveis diferenciados dentro do panorama da hierarquia das forças. A lógica, que neste conjunto pulsante de forças se segue, é única e exclusivamente a busca de assenhoramento, pelo atingir de pontos sempre mais culminantes de potência.

A vida, dentro desta perspectiva nietzschiana, busca sempre se afirmar, alçando níveis mais elevados na escala hierárquica das forças, de modo a ultrapassar a simples condição de homem para atingir a de além do homem. Contudo, este atingir o nível do além do homem não constitui um telos, já que o desafio é incessante, de modo que quanto mais se pensar estar no auge do processo, se está apenas começando. Tudo o que se viveu se vive e se viverá em um número interminável de vezes, num ciclo incessante do retorno. Os grandes eventos da vida, como grandes e pesados desafios, retornarão sempre demandando do homem acolhida e abertura, não com submissão passiva, mas com afirmação ativa. Portanto, todos estes mega eventos demandam uma disposição psicológica capaz de, para além de suportar, amar o grande peso, amar o fato tal como este se apresenta sem subterfúgios ou escusas, mas como todas as forças do querer almejar ultrapassar e superar.

Neste sentido, o norte deste processo de superação de si, como além do homem que acolhe o fato com todas as suas forças num desafio que se desenha num horizonte que sempre retorna é, para além da lei natural que enquadra dentro de um cálculo exato, uma lei que se expressa como vontade de potência. Ou seja, trata-se de uma lei que tem como impulso ativar o querer que supera, em liberdade e afirmação. Com isso, se salvaguarda a livre disposição dos instintos que a todo o momento querem se afirmar, sem que os mesmos instintos sejam capturados pela lógica da razão expressa como lei da natureza. Uma lei afeita à exatidão e a estimativa, portanto, que a todo o tempo responde às expectativas, faz com que resulte um mundo como uma máquina programada. Nesta máquina, os resultados saem tal e qual se estimou, de modo que nada mais de novo e surpreendente pode resultar.

Quando se entrega à lógica do cálculo, se põe toda a esperança na eficácia da razão, precisamente em sua dinâmica causa e efeito. De toda a causa se espera inexoravelmente um efeito, sem margens a qualquer espécie de exceção. À máquina que move os fenômenos da natureza segue uma lei que comanda sem tréguas, de modo a imprimir um caráter de 
superficialidade à própria natureza, já que tudo o que dela resulta não é nada senão o que se previu antecipadamente. A leveza e a flexibilidade dos movimentos que ora presidiram todos os fenômenos naturais, mediante a lei natural, passam a ser substituídos pela dureza e inflexibilidade. Neste movimento, os fenômenos naturais se cristalizam num círculo vicioso marcado pela alternância entre causa e efeito, de modo que nada mais reste a dimensão das perspectivas. $O$ domínio perspectivístico que abre horizontes é sepultado pela radicalidade da lógica viciosa da lei natural que fecha. Enquanto as perspectivas anseiam pela pluralidade e diversidade de interpretações, a lei natural luta por um termo, um fim, um resultado. $O$ excesso de objetividade demandado pela lei natural se reduz a um campo exíguo, à margem de possibilidades que se poderia dar ao criar. A rigidez legal do funcionamento da natureza convoca a conferir resultados e não contemplar a criação artística. $O$ formalismo da lei não cede espaço à criação, aquela que, de acordo com Nietzsche, seria capaz de realizar a grande redenção da humanidade, pelo seu mergulhar no turbilhão incessante de interpretações.

Diante de uma lei natural, engessada em seus mecanismos de medição e previsibilidade, é possível dar vazão à vida que se afirma pela abertura e afirmação? Em que medida a lei natural poderia ser favorável a proliferação da vida em todos os seus aspectos? Pelo rigor da lei natural se é possível operar na lógica das forças que lutam por se afirmar enquanto pontos culminantes de potência? Busca-se responder a estas questões mediante um itinerário que se percorre em três momentos. Se principia apresentando a leitura nietzschiana da lei natural, bem como as diferentes referências que faz a autores e correntes para fundamentá-la, a qual se intitula "A lei natural na literatura nietzschiana". Na sequência, se mostra como a lei pode ser lida dentro da concepção das forças como vontade de potência, para o qual se intitula "A vontade de potência como lei da vida". Para, finalmente, apresentar um balanço de tudo o que da concepção de lei natural se é capaz de apresentar como útil à afirmação da vida, se intitula "A lei natural em sua utilidade à vida".

\section{A lei natural na literatura nietzschiana}

Nietzsche apresenta, em seus escritos, trinta e nove menções a respeito da lei natural. Estas referências sobre lei natural se encontram em seus textos publicados, em seus cadernos, em seus fragmentos póstumos e em seu espistolário ${ }^{2}$. Em todas estas referências, o filósofo alemão deixa entrever quanto à lei natural uma crítica, a de se destituir a natureza ${ }^{3}$ daquilo que esta possui em termos de flexibilidade, fluidez e mobilidade para enquadrá-la nos moldes da

\footnotetext{
${ }^{2}$ Para as citações das obras de Nietzsche adotamos a Edição Crítica Alemã Colli \& Montinari: KSA (Sämtliche Werke: Kritische Studienausgabe) e das Cartas KGB (Sämtliche Briefe Kritische Studienausgabe); após a sigla indicando a obra, em Alemão/Português: GT/NT - Die Geburt der Tragödie (O nascimentoda tragédia), DS/Co Ext I - Unzeitgemässe Betrachtung. Erstes Stück: David Strauss: Der Bekenner und ser Schrisftsteller (Considerações extemporâneas I: David Strauss, o devoto e o escritor), HL/Co. Ex. II - Unzeitgemässe Betrachtung: Zweites Stück: Vom Nutzen und Nachteil der Historie für das Leben (Considerações Extemporâneas II: Da utilidade e desvantagens para a vida), Co.Ext. IV - Unzeitgemässe Betrachtung. Viertes Stück: Richard Wagner in Bayreuth (Considerações extemporâneas IV: Richard Wagner em Bayreuth), MA/HH - Menschliches Allzumenschliches (vol. I) / Humano demasiado humano (vol. I), VM/OS - Menschliches Allzumenschliches: Vermischte Meinungen (Humano demasiado humano) (vol. 2): Miscelânea de opiniões e sentenças), FW/GC - Die fröhliche Wissenschaft (A gaia ciência), JBM/BM - Jenseits von Gut und Böse (Para além do bem e do mal), BA/EE - Uber die Zukunft unserer Bildungsanstalten (Sobre o futuro dos nossos estabelecimentos de ensino), WL/VM - Über Wahrheit und Lüge im aussermoralischen Sinn (Sobre verdade e mentira no sentido extramoral), $\mathrm{Nc} / \mathrm{FP}$ - Nachlass (Fragmentos Póstumos), Br/Cr - Briefe (Carta), segue o número, em romano, indicado o capítulo, se tiver, o número do aforismo, KSA ou KGB, o número do volume e a página.

${ }^{3}$ Nietzsche concebe a lei natural como uma espécie de antinatureza, "[...] o termo "natureza", "lei natural" está completamente ausente: tudo é moral, "milagres" não são nada "antinatural" (porque não há natureza)." ( Nc/FP de novembro de 1887 e março de 1888, 11[394], KSA, 13.184).
} 
determinação, que decorre dos dispositivos jurídicos, expressos em símbolos ${ }^{4}$. Uma influência básica em Nietzsche sobre o tema da lei natural provém de African Spir ${ }^{5}$, como Curt Paul Janz se expressa: "Uma ideia básica e uma atitude pessoal básica de Spir tinham exercido uma influência considerável sobre Nietzsche: 'A lei moral provém de nós, não de Deus, ela é nossa própria melhor natureza!"” (JANZ, 2015, p. 69). Desse modo, se a lei moral, ao provir de nós mesmos, é nossa melhor natureza, então todo o ordenamento moral, em última análise, não passa de balizamentos interpostos pelo próprio ordenamento natural, cujo ser humano é parte integrante do mesmo. Nietzsche sente ser subjugado por uma lei natural, "[...] está sujeito a esses extremos como que a uma lei natural, que pode ser constatada em quase todas as pessoas criativas" (JANZ, 2015, p. 287). Como parte do todo da natureza, o ser humano não pode se furtar aos mecanismos ordenadores que dela se depreendem. O próprio Nietzsche, em uma carta a Heinrich von Stein de 22 de maio de 1884, assim se expressa: "A lei que está acima de mim, minha tarefa." (Br/Cr à Heinrich von Stein de 22 de maio de 1884, KGB, 6.508). É impossível se eximir da influência que a lei exerce sobre a vida, sendo, portanto, uma tarefa observá-la.

Antes, propriamente, de nos debruçar sobre o problema da lei natural, é importante esclarecer que o pensamento de Nietzsche, apesar de sua face negativa, ou seja, crítica, expressa pela transvaloração de todos os valores, pela vontade de potência e pelo além do homem, remete também a um elemento positivo, expresso pelo eterno retorno do mesmo e pelo amor fati. Por essa razão, como recorda André Luís Mota Itaparica "[...] é importante ressaltar que sua filosofia, ao investigar a gênese da moral, não se reduz à crítica, mas também comporta um aspecto normativo. Para Nietzsche, o papel fundamental do filósofo na cultura é o de legislar." (ITAPARICA, 2016, p. 282). O filósofo legislador tem um papel fundamental no cultivo da espécie humana ${ }^{6}$, o que aproxima a filosofia de Nietzsche ao aspecto político do pensamento platônico. Desse modo, a própria natureza encontra-se submetida ao governo de leis, pois, como recorda Asheley Woodward "[...] embora Nietzsche nunca use o termo 'naturalismo', ele evocou uma 'divinização da natureza' e uma 'naturalização do homem" (WOODWARD, 2016, p. 312). A natureza constitui, com um homem, uma totalidade indissolúvel. " $O$ projeto naturalista de Nietzsche, pois, não adota a descrição científica da natureza pura e simplesmente, mas, antes, critica essa descrição em nome de um naturalismo mais radical." (WOODWARD, 2016, p. 325). A busca desenfreada pelas ideias claras e distintas faz com que se lance no abismo dos antípodas, de modo a se estabelecer, com exatidão, que uma coisa seja isso ou aquilo, como se a natureza fosse governada por leis externas a ela. O próprio conceito de natureza é, segundo Oswaldo Giacóia Júnior, associado ao "[...] de regularidade derivado das leis [...] constituem os objetos da experiência, relações subsumidas sob o conceito de leis naturais" (GIACÓIA, 2013, P. 32). Pensar uma natureza submetida ao governo de leis é como:

Se agora alguém demonstra de maneira convincente que por essa via direta não é dado alcançar a meta antípoda, quem há de querer continuar trabalhando nos velhos poços, a não ser que entrementes se dêpor satisfeito em encontrar pedras preciosas ou em descobrir

\footnotetext{
4 "Simbolismo infinitamente inadequado, desenvolvido de acordo com leis naturais fixas: na escolha do símbolo não há liberdade, mas instinto. Um símbolo notável agora é um conceito: você entende o que pode designar e distinguir." ( $N c / F P$ do inverno de 1869 a primavera de 1870, 3[15], KSA, 7.63-4).

5 Afrikan Aleksandrovich Spir (1837-1890) foi um filósofo russo neo-kantiano de descendência alemão-grega que escreveu principalmente em alemão. Seu livro Denken und Wirklichkeit exerceu um "impacto duradouro" nos escritos de Friedrich Nietzsche.

${ }^{6}$ Inclusive, Fiódor Dostoiébski, quem influenciou grandemente Nietzsche por sua literatura, em seu Crime e Castigo, ressalta sobre a espécie humana que "[...] a repartição dos indivíduos nas categorias e subdivisões da espécie humana, deve ser estritamente determinada por alguma lei da natureza." (Dostoiévski, 1960, p. 239).
} 
leis da natureza? Por isso Lessing, o mais honrado dos homens teóricos, atreveu-se a declarar que lhe importava mais a busca da verdade do que a verdade mesma: com o que ficou descoberto o segredo fundamental da ciência, para espanto, sim, para desgosto dos cientistas (GT/NT, 15, KSA, 1.98-99).

Toda a investigação que se baseia na busca de identificação de algum fundamento para o conhecimento, sejam estes metafísicos ou científicos, por si só se encontram em posição equivocada, portanto, fadadas a sua autodestruição e decadência. Ou ainda, quando se insiste em substituir aquele antigo caminho metafísico pelo de uma regularidade da natureza ${ }^{7}$, nada mais se faz senão contaminar a natureza, que em seu genuíno movimento de transformação e adaptação vai perfazendo o seu caminho. Portanto, é um caminho que a natureza por si mesma dispõe, independentemente de qualquer fator externo, seja como modelo de imitação ou exemplaridade. Para Nietzsche, tampouco é salutar lançar-se à busca de como se dá o conhecimento, pois a busca de se entender o caminho revela a intenção de querer entender para onde este leva, ou seja, a sua teleologia. Como se a própria ciência fosse dotada de um fim, o que dá a entender um sistema doutrinário, fechado em si mesmo uma aeterna veritatis. ${ }^{8}$ Ora, tal concepção só poderia mesmo perturbar a mente de qualquer cientista que tenha um mínimo de sensibilidade e empatia com a ciência. Pois a ciência é mutável, já que se atém a realidades mutáveis, como é o caso da natureza; querer fixá-la resulta num contrassenso. Esta fixação da ciência em leis fixas é, em outras palavras: "A inviolabilidade das leis naturais significa: sensação e memória estão na essência das coisas [...] Todos buscam o prazer e fogem do desprazer, essas são as leis eternas da natureza" ( Nc/FP de 1872, 19[161], KSA, 7.470). A memória como fixação das sensações, das experiências vividas, acaba sendo responsável por sistemas regulares no transcurso natural das coisas. Nietzsche, inclusive, chega a tecer elogios à capacidade humana de esquecer, pois pelo esquecimento todas aquelas forças aprisionadas podem ser descarregadas e assim não se alimenta a consciência com aquelas marcas que se pretendem eternas, como é caso da consciência de culpa. Como as sensações fazem parte da ordem dos instintos, estas não podem ser submetidas ao crivo da memória, já que não se pretendem eternas, mas em movimento contínuo. E neste movimento, sensações de prazer e desprazer fazem parte inevitável da vida, cabendo, portanto, não negá-los, mas os assumir como toda a sua carga. Ora, neste sentido, a lei da natureza da qual se busca prazer e foge do desprazer, dentro da dimensão nietzschiana anímica, é desconstruída, pois afirmar a vida é fazê-lo, inclusive, naquilo que é mais pesado e terrível e não apenas ao que proporciona prazer. Neste sentido, Nietzsche constata que a inviolabilidade das leis da natureza toca uma dimensão errônea e equivocada de natureza, pois acaba submetendo a natureza aos moldes de uma determinação inviolável da forma e que viola o que a natureza tem como distintivo fundamental, a sua mutabilidade. Chega a ser tão equivocada a lei da natureza que "Não se pode falar mais de uma memória não errônea do que de uma ação absolutamente intencional das leis

\footnotetext{
7 "Lei natural" uma palavra de superstição. - Quando você fala tão encantado da regularidade da natureza, você deve presumir que, por obediência livre e auto-submissa, todas as coisas naturais obedecem à sua lei - caso em que você admira a moralidade da natureza -; ou ficará encantado com a ideia de um mecânico operário que fez o relógio mais elaborado, tendo seres vivos como ornamento. - A necessidade na natureza se torna mais humana através da expressão "regularidade" e um refúgio final para devaneios mitológicos. (VM/OS, II, 9, KSA, 2.384).

${ }^{8}$ Nietzsche apresenta a lei da natureza como uma espécie de aeterna veritatis: "Diz-se que é uma lei inviolável da natureza: quem nasce filósofo tem ouro no corpo, quem é guardião, só prata, quem é operário, ferro e minério. Como não é possível misturar esses metais, explica Platão, deveria não ser possível jogar a ordem de castas de cabeça para baixo; A crença na aeterna veritas dessa ordem é o fundamento da nova educação e, portanto, do novo estado. - Então, o alemão moderno agora também acredita na aeterna veritas de sua educação, seu tipo de cultura: e ainda assim essa crença cai porque o estado platônico teria falhado se a mentira de angústia uma vez se opusesse a uma verdade emergencial: que o alemão não tem cultura porque ele não pode tê-los por causa de sua educação." (HL/Co. Ex. II, 10, KSA, 1.328).
} 
da natureza" (Nc/FP de 1872, 19[163], KSA, 7.470). As leis que governam o funcionamento da natureza são permeadas por uma intencionalidade e uma validade eterna ${ }^{9}$ que as torna tão engessadas a ponto de serem incapazes de sofrerem qualquer alteração que seja. Ora, se as leis da natureza se caracterizam por esta inflexibilidade e engessamento, então a memória que serve de impulso a estas leis não podem ser mais nada senão errôneas. Pois, ao pretender eternizar fatos, situações, normas, a memória só pode induzir todas as coisas ao erro: o erro de conceber uma natureza cristalizada em leis, em torno a valores morais ${ }^{10}$.

Diante desta cristalização da natureza em leis Nietzsche se pergunta: quem as cristalizou? Quem as definiu segundo tais e tais leis? Quem as cerceou de acordo com os limites que correspondem às ditas leis? Eis, portanto, as provocações frente as quais se pronuncia: "Todas as leis naturais são apenas relações de um x com y e z. Definimos leis naturais como a relação com um xyz, cada uma das quais, por sua vez, só é conhecida por nós como relação com outro xyz" (Nc/FP de 1872, 19[235], KSA, 7.493). Somos nós que definimos tais leis com base em relações ${ }^{11}$ entre incógnitas, ou seja, não passam de hipóteses, das quais pretendemos derivar uma lei inalterável. Este processo de atribuição às leis da natureza com base na atribuição de relações entre incógnitas chega a ser tão artificial, ao ponto de que passamos a reconhecer tais relações somente mediante as hipóteses que criamos, portanto, puro antropomorfismo ${ }^{12}$. Logo, as leis não passam de criações humanas, razão pela qual se faz urgente o trabalho de estabelecimento de uma genealogia destas leis. É preciso estabelecer sob quais condições as criamos, com que meios e sob quais critérios as avaliamos, a fim de chegarmos àquelas avaliações que não mais podem ser avaliadas. Este trabalho do estabelecimento de uma genealogia das leis da natureza vai variar para quem o realiza, desde um cientista até um artista: "O homem de ciência calcula os números das leis naturais, o artista olha para elas: - Lei ali, beleza aqui. O que o artista vê é muito superficial, não uma "ideia"! A capa mais leve em torno de belos números" ( $N c / F P$ de 1872, 23[42], KSA, 7.558). Enquanto o cientista realiza um cálculo preciso das leis da natureza, de modo a concebê-la em toda a sua exatidão e previsibilidade ${ }^{13}$, o artista a contempla naquilo que esta

\footnotetext{
9 "Em relação a toda a nossa experiência, devemos sempre permanecer céticos e, por ex. dizer: não podemos reivindicar uma validade eterna de qualquer "lei natural", não podemos reivindicar sua persistência eterna de qualquer qualidade química, não estamos suficientemente bem para ver o suposto fluxo absoluto de eventos: o que resta está lá apenas em virtude de nossos órgãos densos que se combinam e depositam em superfícies o que não existe." (Nc/FP de 1881, 11[293], KSA, 9.554).

10 "Com que ingenuidade aplicamos nossos valores morais às coisas, quando falamos de leis naturais! Seria útil tentar uma forma completamente diferente de interpretá-lo: para que, por amarga contradição, se possa compreender como inconscientemente nosso cânone moral (preferência pela verdade, lei, razoabilidade etc.) governa toda a nossa dita ciência." ( $N c / F P$ de agosto e setembro de 1885, 39[14], KSA, 11.625).

11 "Então: o que é uma lei da natureza para nós em geral? não é conhecido por nós per se, mas apenas em seus efeitos, ou seja, em suas relações com outras leis naturais, que novamente só conhecemos como relações. Assim, todas essas relações referem-se apenas umas às outras repetidamente e são, por sua natureza, incompreensíveis para nós por completo; só sabemos realmente o que adicionamos, tempo, espaço, ou seja, sucessões e números. Tudo o que é maravilhoso, porém, que nos espanta nas leis da natureza, que exige nossa explicação e que poderia nos levar a desconfiar do idealismo, reside unicamente no rigor matemático e na inviolabilidade das concepções de tempo e espaço." (WL/VM, I, KSA, 1.885).

12 "Ele nos ensina a reconhecer que exigir uma exceção à execução de uma única lei natural, isso significaria exigir a destruição do universo." Pelo contrário, Sr. Magister: um cientista natural honesto acredita na lei incondicional do mundo, mas sem a menor parte da ética ou para expressar o valor intelectual dessas próprias leis: em tais afirmações ele reconheceria o comportamento altamente antropomórfico de uma razão que não se limita ao que é permitido." (DS/Co Ext. I, 7, KSA, 1.197).

${ }^{13}$ Frente ao excesso de regularidade do cientista, Nietzsche apresenta o artista como aquele que, na qualidade de um asceta, anseia por alcançar os mais altos níveis da contemplação. "- Bem, assim como o amante se sente agora, em termos de natureza e naturalidade, o mesmo acontecia com todo adorador de Deus e de sua "santa onipotência": com tudo o que foi dito da natureza, por astrônomos, geólogos, fisiologistas, médicos ele viu uma invasão de seus bens mais preciosos e, consequentemente, um ataque - e ainda por cima uma falta de vergonha por parte do atacante! A "lei natural" soou para ele como uma calúnia contra Deus; Basicamente, ele teria adorado ver toda a mecânica atribuída a atos morais de vontade e arbitrariedade: - mas porque ninguém poderia prestar-lhe este serviço, ele escondeu a natureza e a mecânica o melhor que pôde e viveu em sonhos." (FW/GC, 59, KSA, 3. 423).
}

FEILER, Adilson Felicio. A lei natural como vontade de potência: considerações nietzschianas acerca da legislação da natureza. Griot : Revista de Filosofia, Amargosa - BA, v.21 n.3, p.375-389, outubro, 2021. 
possui de aparência, para além de uma ideia e teoria. Nietzsche parece, com esta comparação entre os dois olhares, o do cientista e o do artista, impulsionar um olhar de artista para com as leis naturais, para mostrar o quanto há de mutável e aparente nestas, e, ao mesmo tempo, é nesta mesma mutabilidade e aparência que reside a sua beleza. Novamente Nietzsche convoca o trabalho do filósofo artista para a realização desta importante empreitada, a de traduzir as leis da natureza mediante o crivo da leveza e da sensibilidade.

Desta avaliação das leis da natureza feitas pelo artista, o que resta não é nada senão a sensação, ou seja, aquilo que se experimenta como fruição artística, como gosto, aparência e elevação estética. "A sensação é o único fato fundamental que conhecemos, a única qualidade verdadeira. Todas as leis da natureza podem ser rastreadas até as leis do movimento: absolutamente sem matéria. Quando terminar, você terá apenas estabelecido as leis da sensação. Nada se ganha pelo "em si" ( $N c / F P$ de 1873, 27[37], KSA, 7.598). Mesmo que se realize todo um trabalho de análise técnico-científica sobre o funcionamento das leis da natureza, ao fim e ao cabo, resultará nada senão o que se experimentou em termos de sensação, ou seja, de experiência. $O$ filósofo alemão compreende a impossibilidade de reduzir as diferentes experiências vividas, mediante os sentidos, às abstrações racionais que se pretendem traduzir em leis tais experiências. A tradução das experiências sensíveis em leis e teorias racionais conduz inevitavelmente ao óbito de tais experiências, e, consequentemente, a uma compreensão errônea sobre o funcionamento da natureza. Dado que este funcionamento somente se dá mediante a dimensão de luta, e neste as forças possuem um papel fundamental, é imprescindível mergulhar nesta dimensão anímica a fim de se compreender o funcionamento de tais leis. Por essa razão, segue-se aprofundando esta análise, neste segundo momento, pelo aprofundamento da dimensão das forças enquanto propulsoras do funcionamento das leis na natureza como vontade de potência.

\section{A vontade de potência como lei da vida}

A vida em Nietzsche se reveste inteiramente das perspectivas das forças. Portanto, nada escapa ao turbilhão anímico constituído pela tensão entre osbstáculos que a todo o momento se interpõem e resistência que se lhe opõem; tudo isso num movimento contínuo, de modo que quando tudo parece estar resolvido, novamente outros obstáculos se apresentam, numa luta eterna e irresoluta. Alan D. Schrift entende a vontade de potência como "[...] relações de força: forças de atração e repulsão, dominação e subordinação, imposição e recepção" (SCHRIFT, 2017, p. 409). Diante dessa luta incessante, se pergunta se não há nada que possa orientar estas forças no sentido de não limitá-las, mas dotá-las de um quantum mais potente e mais culminante. A fonte de orientação e comando destas forças se encontra, dentro da perspectiva nietzschiana, na vontade. "Nietzsche descreve essa imagem divinizada da natureza como 'caos" ou 'a inocência do vir a ser', mas a mais conhecida imagem desdivinizada do mundo em seu pensamento é o mundo como vontade de potência." (WOODWARD, 2016, p. 326). É pela vontade que se encontra a mola propulsora da força, por isso se fala em vontade de potência ${ }^{14}$, ou seja, vontade de sempre

\footnotetext{
14 "Ni dieu, ni maître "- é assim que você também quer: e, portanto," acima da lei da natureza "! - Não é? Mas, como eu disse, isso é interpretação, não texto; E poderia vir alguém que, com a intenção oposta e a arte da interpretação, da mesma natureza e em relação aos mesmos fenômenos, entenderia precisamente a afirmação tirânica, implacável das reivindicações de poder - um intérprete que na ausência de exceção e incondicionalidade toda a "vontade de poder" apresentada a você de tal forma que quase todas as palavras e até mesmo a palavra "tirania" acabariam parecendo inutilizáveis ou mesmo como uma metáfora debilitante e atenuante - como muito humana; e que, no entanto, terminou reivindicando sobre este mundo a mesma coisa que você afirma, a saber, que ele tem um curso "necessário" e "calculável", não porque as leis o regem, mas porque absolutamente as leis estão ausentes, e todo o poder tira suas conclusões finais a cada momento." (JGB/BM, 22, KSA, 5.37).
} 
mais força, movida pela única lei natural existente, a lei da contraposição ${ }^{15}$ : "[...] um duplo uso da vontade de poder de Nietzsche. Quer seja um continuum de poder-conhecimento ou de "produção desejante" (SCHRIFT, 2017, p. 410).

Com a lei da vontade de potência assiste-se a um choque com a lei da natureza, como se vontade de natureza fossem duas realidades diametralmente opostas. A vontade não pode ser governada com aquela mesma precisão a que se pretende a ciência, com a sua lógica de precisão e infalibilidade, mas "[...] instrumentaliza a totalidade dos entes, mobilizando-os para fins de cálculo e rentabilidade" (GIACÓIA, 2013, p. 58). Trata-se, ainda, como recorda Werner Stegmaier, de "[...] um novo "poder incondicionalmente potenciador' na vontade de poder" (STEGMAIER, 2013, p. 40).

Certamente, cada pessoa que se sente à vontade em tais considerações sentiu uma profunda desconfiança de qualquer idealismo, tão freqüentemente quanto ele já esteve claramente convencido da consistência eterna, onipresença e infalibilidade das leis da natureza; Concluiu: aqui está tudo, até onde podemos penetrar, de acordo com a altura do telescópico e a profundidade do mundo microscópico, tão seguro, desenvolvido, infinito, regular e sem lacunas; a ciência terá que cavar para sempre com sucesso nesses poços e tudo o que for encontrado irá concordar e não se contradizer ( $W L / \mathrm{VM}, 1$, KSA, $1.885)$.

A princípio básico da ciência é não se contradizer, ou seja, encontrar certeza em todas as coisas, de modo que tudo seja calculado de forma precisa, regular e sem lacunas. A vontade, que se expressa como força, escapa a toda a regularidade e precisão do cálculo minucioso, tal como adotado pela ciência. O operar da vontade extrapola com todos os mecanismos científicos submetidos a regularidade dos fatos. Estes mesmo fatos, entendidos em sua regularidade, segundo Jörg Salaquarda "[...] dependem principalmente da força e coragem da "vontade de poder" (SALAQUARDA, 2017, p. 135). A expressão da vontade é a pura busca de assenhoramento, de alçar os mais altos cumes da potência, “[...] uma vontade de apropriação e de intensificação, a qual, como um si-mesmo, alcança perspectivamente sempre mais além" (STEGMAIER, 2013, p. 49). Portanto, as leis da natureza são submetidas ao rigor de um fluxo incessante, se há alguma lei, esta não pode ser outra senão a do movimento e luta constantes, um verdadeiro campo de batalha $^{16}$. Sempre que pensamos algo como fluido "[...] o rigor das leis naturais cessa. As leis da sensação - como o núcleo das leis da natureza. Mecânica dos movimentos. Crença no mundo exterior e no passado, na ciência. A coisa mais verdadeira neste mundo - ame a religião e a arte." (Nc/FP de 1873, 29[8], KSA, 7.625-6). A sensação possui leis que a governam, contudo sem a limitar, mas provocar ainda mais potência. Eis, portanto, o sentido destas leis no tocante à natureza: promover um quantum sempre mais potente de força. As leis pensadas enquanto propulsoras de forças, amenizam o seu teor legal para aguçar o seu teor instintual e anímico. Tudo o que reforça a razão e a ciência passa a ser direcionado para o âmbito da intuição e da estética. Desse modo, a lei natural, em Nietzsche, existe na medida em que destaque a lei da vida, entendida

\footnotetext{
15 Nietzsche promove que toda as contraposições atinjam o poder, pois nelas a lei da natureza encontra o seu valor sentido. "Faça com que as visões opostas cheguem primeiro ao poder, por exemplo, lei natural estrita, desamparo e superfluidade de todos os deuses, compreensão mais estreita da alma como um processo físico - então acabou. Agora, toda a cultura grega se apoia nessas opiniões." (Nc/FP de 1875, KSA, 8.42).

${ }_{16}$ Assim, no sistema planetário, na política das nações. A lei natural de todos os indivíduos é muito complicada, sejam eles seres vivos ou partículas inanimadas de matéria; uma grande batalha se desenrola, o campo de batalha muitas vezes está escondido de nós; Não vemos o que os seres individuais fazem nele, mas podemos julgar o resultado da luta, mesmo muitas vezes predizê-lo. ( $N c /$ FP de 1875, KSA, 8.182).
} 
enquanto propulsora de força criadora, e por esta força nada escapa ${ }^{17}$. Neste aspecto, também a religião constitui uma força criadora, na medida em que conduz a manifestação das pulsões anímicas, de modo que a condução da vida se dê para além do âmbito moral - " [...] a doutrina da vontade de poder também aparece como uma doutrina através da qual a vida deveria ser compreendida de maneira mais profunda e livre [...] a 'essência da vida' deveria ser novamente formulada em uma "teoria universal" (STEGMAIER, 2013, p. 79). Esta teoria universal reflete uma espécie óleo calmante universal, como lemos:

Se alguma vez um deus e uma pessoa foram mal aconselhados, ainda é este Deus Straussiano que errou e não tem o hobby, e o homem Straussiano que tem que expiar este hobby - aqui se ouve, é claro, “um significado de escopo infinito, o óleo calmante universal de Strauss flui para lá, e suspeita-se da razoabilidade de todo devir e de todas as leis naturais! Realmente? Não seria nosso mundo, como Lichtenberg certa vez disse, o trabalho de um ser subordinado que ainda não entendeu realmente o assunto, isto é, uma tentativa? (DS/Co Ext. I, 7, KSA, 1.198).

É preciso pensar um deus e uma religião para além daquela pensada por David Strauss. Portanto, é preciso apresentar uma religião que encarre todo o devir com inocência afirmativa e não com suspeitas e limitantes morais. Pensar um deus e uma religião para além de leis que sucumbem e tornam o homem culpado. Na medida em que a lei subjuga, torna culpado e apazigua, não é capaz de promover um deus e uma religião que fomente a vontade de criar e, assim afirma a vida. Do contrário, a lei atua como agente inibidor da manifestação da descarga das forças, de modo a direcioná-las para dentro, ao invés de promover a sua externação. Pois a força, dentro de uma crença religiosa, na medida em que se direciona para dentro resulta em culpa, má consciência e ressentimento. Ao contrário, na medida em que se direciona para fora promove criação artística. E é como obra de arte que a vida pode se expressar enquanto quantum sempre mais potente de forças.

Enquanto a vida for submetida a ter que quitar uma dívida, a ter que sucumbir à logica da lei da causalidade, jamais poderá se afirmar enquanto potência ativa e criadora. Na medida em que as leis forem compreendidas como inalteráveis, como sistemas fixos e intocáveis, as forças passam a sofrer um golpe frontal em sua capacidade de expansão.

Os pesquisadores da história animal se empenham em apresentar os surtos de violência, astúcia e vingança na atual relação sexual entre estados e pessoas como leis inalteráveis da natureza. Os historiadores estão ansiosos por provar a proposição de que todo tempo tem seu próprio direito, suas próprias condições - a fim de preparar as ideias básicas de defesa para o julgamento que se aproxima com o qual nosso tempo será afligido (Co/Ext. IV, 6, KSA, 1.463).

Nietzsche mostra o quanto a vida sucumbe com as leis que imperam no tempo determinado em que se vive. Como cada um acaba por sofrer obstrução em sua capacidade de se afirmar na medida em que é refém de seu tempo, de sua história. Por essa razão, o filósofo leva a refletir sobre como se pode conceber a história para além das amarras dos modelos tradicional, monumental e crítico. De modo a conceber a história em sua capacidade de ser útil para a vida. Ou seja, que nenhum daqueles elementos da tradição, daqueles emblemas do passado e esquemas críticos impeçam a vida naquilo que ela tem como seu aspecto mais original: a sua capacidade de

\footnotetext{
17 "Vontade de poder como "lei natural" Vontade de poder como vida Vontade de poder como arte. Vontade de poder como moralidade. Vontade de Poder como Política Vontade de Poder como Ciência. Vontade de poder como religião." (Nc/FP da primavera de 1888, 14[71], KSA, 13.254).
} 
criar, e, assim de se fortalecer e se fortificar. As leis da natureza utilizadas pelo historiador nem sempre propiciam à vida a flexibilidade e mutabilidade de que necessita para se fortificar, no sentido de seu assenhoramento. "As leis naturais do desenvolvimento da arte são, na verdade, consequências de coisas psicológicas, vaidade, ambição, etc." (Nc/FP de 1878, 30[137], KSA, 8.546). Quando as leis naturais excedem os limites impostos pela moral, negadora dos instintos, e pela razão, desmanteladora da intuição, serão capazes de promover a vida, mediante a arte, precisamente naquilo que a torna um campo anímico, de forças que querem prevalecer, “[...] como princípio de um novo estabelecimento de valores" (STEGMAIER, 213, p. 255). Tais forças como a vaidade, a ambição, a cobiça de mais, são lidas no âmbito moral como más, como aliciadoras do ser humano, portanto, como destituídas das qualidades que devem prover o humano em todas as suas dimensões. Este âmbito moral, acima descrito, é, precisamente, o âmbito do sacerdote ascético, apresentado por Nietzsche na Terceira Dissertação de Para a Genealogia da moral. O instinto sacerdotal é o contra instinto, na medida em que, na qualidade de vampiro, se alimenta do sentimento de culpabilidade daqueles que estão submetidos a sua direção espiritual.

Nesta altura da reflexão, pergunta-se em que medida a lei natural, para além de toda a instrumentalização comandada pela moral e pela razão científica, pode ser válida para a vida. Em que aspectos a lei natural pode promover a vida, no sentido de torná-la afirmativa, de concebê-la como nutriente promotor de forças capazes de conduzir a vontade de potência para o âmbito da inocência.

\section{A lei natural em sua utilidade à vida}

Pelo caminho percorrido até aqui, pode se constatar que as leis naturais não são pensadas, por Nietzsche, como um problema em si mesmas. Mas sim, que estas leis naturais, ao se tornarem obstáculos para a vida, podem ser um problema. Neste sentido, a questão está em garimpar, pela reflexão nietzschiana, em que aspectos e situações uma lei natural se coloca contra a vida. Ora, nestes casos concretos, Nietzsche convoca a se colocar "Contra as chamadas leis naturais e principalmente as econômicas etc." (Nc/FP de 1879, 44[6], KSA, 8.612). Na medida em que as leis naturais se investem contra a vida, naquilo que a caracteriza como força anímica, passam a ser consideradas como anti-vitais, e, por essa razão, devem ser eliminadas.

É importante estar atento sobre como uma lei passa a se estabelecer como tal. Nenhuma lei já existiu desde sempre, mas foi no decorrer do tempo, mediante comportamentos repetidos com uma certa frequência, se tonando hábitos que acabam por ser regulados. "Mesmo as leis da natureza são apenas hábitos longos. Desde que se tenha uma vontade forte, uma filosofia cética é melhor para fazer com que sua vontade funcione da melhor maneira possível." ( $N c / F P$ do 1883 , 15[50], KSA, 10.493). Nietzsche defende a tese de que nenhuma lei natural pode ser mais forte que uma vontade, pois, por essa mesma vontade se é capaz de lutar contra uma série de situações que se pretendem estabelecer como verdade última. Enquanto uma lei apenas regula o que se mostra ser sempre o mesmo, a vontade ousa o novo, ousa ultrapassar, inovar, despir o véu que encobre uma série de realidades que se mostraram incapazes de se ultrapassarem. Enquanto a vontade se impõe apontando maneiras diferenciadas de ler a realidade,

[...] - as alegadas "leis da natureza" são as fórmulas para "relações de poder" de - - A maneira mecanicista de pensar é uma filosofia de primeiro plano. Educa para estabelecer as fórmulas, traz consigo um grande alívio - os diferentes sistemas filosóficos devem ser considerados como métodos educacionais do espírito: eles sempre desenvolveram melhor um poder especial do espírito; com sua demanda unilateral de ver as coisas desta forma e não de outra forma. ( Nc/FP de 1885, 34[247], KSA, 11.504). 
As relações de poder que o filósofo realça estão entre aspas, por isso, apontam para o contrário daquilo que seria uma relação promotora de força, mas uma relação causa e efeito ${ }^{18}$. Portanto, trata-se de uma relação racional, incapaz de se impor, no sentido de lutar por mais potência, de onde se pode derivar a vida. Mas, ao contrário, encolhe-se e se resigna sob o peso de fórmulas mecânicas, desenvolvidas de acordo com uma maneira unilateral ${ }^{19}$ de conceber a vida. "Nietzsche critica a concepção mecanicista do universo como composto por átomos entendidos como as menores coisas existentes em um sistema governado por leis necessárias de causa e efeito" (WOODWARD, 2016, p. 349). Frente a essa unilateralidade, Nietzsche se impõe com a sua visão perspectiva, diante da qual nada se pode conceber como a última palavra, ou seja, como uma verdade eterna e acabada. "A perspectiva'. 'Leis da natureza' como determinação das relações de poder. "Causa e consequência" uma expressão para a necessidade e inexorabilidade desta determinação de poder. Liberdade de vontade e poder." (Nc/FP de 1885, 39[12], KSA, 11.623). A visão perpectivística é colocada como contraposta às leis da natureza. Enquanto aquela primeira promove relações de poder, entendidas como um quantum sempre maior de força, as segundas se impõem como mantenedoras de um determinado estado de ordem, diante do qual tudo é inexoravelmente estabelecido. Neste sentido, o poder que dali se depreende se impõe para preservar, ao invés de ultrapassar e alcançar pontos mais culminantes de força. Numa visão perspectiva a vida se afirma, na medida em que cada visão se impõe no sentido de alcançar a sua plenitude, para além de toda a causalidade natural ${ }^{20}$, num jogo eterno de forças que se configuram hierarquicamente. Sob esta aspecto, numa versão perspectiva a verdade é substituída pela aparência, e esta luta por se afirmar. "Os seres" como aparência; Inversão de valores: a aparência era o que conferia valor - o conhecimento em si mesmo tornando-se impossível; então, como o conhecimento é possível?" ( Nc/FP de 1886, 7[54], KSA, 12.312-3). Nietzsche estabelece, mediante um conjunto de elementos, e entre estes as leis da natureza, as condições mediante as quais os seres são submetidos a transformações. $O$ que revela, portanto, a impossibilidade de que destes seres possa se derivar alguma forma de conhecimento que se estabeleça como verdade eterna e imutável. Neste sentido, cabe novamente a pergunta: em que medida as leis naturais podem ser úteis para a vida. Entendendo, é claro, que estas leis estejam submetidas unicamente aos critérios do devir. Critérios estes que concebem todo o "foi desta ou daquela forma" como um "poderia", assim as leis que governam a natureza podem em si mesmas engendrar a dimensão metamórfica. As leis assim entendidas fazem do mundo não um mundo verdadeiro, mas um mundo aparente, carregado da força simbólica.

Se eu entendo algo sobre este grande simbolista, é que ele só viu e reconheceu realidades
interiores: que ele entendeu o resto (tudo natural, histórico, político) apenas como sinais
e oportunidades de parábola - não como realidade, não como "mundo verdadeiro" ... Da
mesma forma, o filho do homem não é uma pessoa concreta da história, mas um "fato
eterno", um símbolo psicológico não travado no tempo ... O mesmo é finalmente verdade
mais uma vez do Deus deste típico Simbolista ... do reino de Deus, do "reino dos céus" ...

18 "Porque na interpretação do mundo mecanicista ainda é necessário um móvel. - 'Direito natural': como fórmula para o estabelecimento incondicional de relações e graus de poder. - o movimento mecânico é apenas um meio de expressar um evento interno. - "Causa e efeito"" ( $N c / F P$ do outono de 1885 a primavera de 1886, 1[30], KSA, 12.17-8).

19 'Esse 'um em cima do outro' ainda precisa ser interpretado: 'Lei natural' é uma interpretação etc. 'Causa e efeito' remonta ao termo 'ação e perpetrador'. De onde veio esse divórcio? O movimento como sintoma de um evento não mecânico.” ( $N c / F P$ do final de 1886 e primavera de 1887, 7[34], KSA, 12.306).

20 "Naquela época, ainda nada sabemos sobre as leis da natureza; não há obrigação nem para a terra nem para o céu; uma estação, o sol, a chuva pode vir ou não. Não existe nenhum conceito de causalidade natural.” (MAI/HHI, 111, KSA, 2. 112). 
o "pai" e o "filho": o último expressa a entrada nesse estado de transfiguração total de todas as coisas, o primeiro é exatamente isso ... - e essa ideia foi mal compreendida até agora a história de Anfitrião (um adultério mal mascarado) foi colocada na cabeça da nova fé (junto com a ideia hedionda de uma concepção imaculada: como se em si mesma a concepção e o que seria contaminado -) A degeneração profunda 1) por querer entender historicamente 2) por querer ver milagres (- como se fosse sobre quebrar e superar leis naturais!) 3) - - - (Nc/FP de 1888, 11[355], KSA, 13.155).

A força simbólica aponta para elementos psicológicos que, na dimensão de símbolos, não engessam em realidades concretas e determinadas, mas vislumbram um fato, um instante pleno que se transfigura em pontos culminantes de potência. Como se trata de figuras, que psicologicamente se configuram como uma unidade plena, não estão em condições de serem submetidas a um esclarecimento histórico que as estilhasse em fragmentos do entendimento, e tampouco em comprovação de milagres pela superação de leis naturais. Neste sentido, as leis naturais poderiam até ser classificadas como úteis à vida ${ }^{21}$, na medida em que impedem a justificação de fatos que extrapolam o mundo, entendido como campo de forças. "Talvez seja uma lei da natureza que apenas as gerações posteriores tenham que se conscientizar dos dons celestiais com que uma anterior foi homenageada." (BA/EE, 4, KSA, 1.723-4). Que lei da natureza anterior seria esta que Nietzsche estaria aqui apresentando, senão aquela que se assenta na quebra dos paradigmas do conhecimento, para apontar para as leis naturais que governavam o mundo dos gregos antigos, anteriores à virtude da simplicidade do conhecimento socrático. As leis que se desfazem das amarras da rigidez do conhecimento racional abrem espaço às leis iluminadas com a luz da intuição. Se constitui assim, uma "[...] unidade de 'nosso poder lógico-poético' [...] no entrelaçamento entre arte e ciência" (STEGMAIER, 2013, p. 230). São aquelas leis que se dissolvem em metáforas e que se lançam ao campo perspectivístico. "Cada lei da natureza é, em última análise, uma soma de relações antropomórficas. Principalmente o número: a dissolução de todas as leis na multiplicidade, sua expressão em fórmulas numéricas é um $\mu \varepsilon \tau \alpha \varphi \rho \rho \alpha ́$ " ( $N c / F P$ de 1872, 19[237], KSA, 7.494). As leis são, dentro da perspectiva de multiplicidade interpretativa, metáforas. Portanto, a rigidez lógica e racional das leis, ao se dissolver na multiplicidade interpretativa, as torna um conjunto infinito de figuras a comporem o universo de pulsões.

Então: o que é uma lei da natureza para nós em geral? não é conhecido por nós de per se, mas apenas em seus efeitos, ou seja, em suas relações com outras leis naturais, que novamente só conhecemos como relações. Assim, todas essas relações referem-se apenas umas às outras repetidamente e são, por sua natureza, incompreensíveis para nós por completo; só sabemos realmente o que adicionamos, tempo, espaço, ou seja, sucessões e números. (WL/VM, 1, KSA, 1.885).

A lei em si, no contexto das forças, não tem sentido, mas enquanto relações que se estabelecem entre leis. Por estas relações se pode constatar como as leis passam a formar uma multiplicidade disposta hierarquicamente. Eis, uma grande contribuição que as leis podem oferecer à vida: sua multiplicidade em relações de domínio de umas sobre as outras, com a busca de assenhoreamento. Esta multiplicidade das leis, que se encontram dispostas numa situação factual, não se interessa em investigar o porquê algo é o que é, mas simplesmente que algo é. O que poderia soar como uma constatação estúpida, do ponto de vista daqueles que submetem as leis a complexidade de uma análise racional e moral, o que de per si eliminaria a própria dimensão

\footnotetext{
21 Dentro de âmbito da vontade de potência, "Cada um pode, na sua própria situação, experimentar a necessidade da vida de maneira diferente" (STEGMAIER, 2013, p. 259).
} 
de natureza ${ }^{22}$. "Eles de alguma forma equivalem a uma lei natural ou uma lei legal? Não diz 'você deveria', mas 'infelizmente foi assim'. É a expressão de uma relação factual estúpida em que ninguém está procurando por quê?"” (Nc/FP de 1873, 29[41], KSA, 7.643). A lei, em sua utilidade à vida, se expressa como relação factual, ou seja, como leis que se relacionam em consonância a expressão dos fatos na inocência de sua apresentação.

\section{Considerações finais}

As análises referidas no decorrer da investigação permitiram dar algumas pistas sobre a posição de Nietzsche a respeito da lei natural. A questão não está em se o filósofo alemão é contra ou a favor da lei natural. Mas, em que aspectos e sob quais circunstâncias a lei natural pode contribuir para o valor fundamental que move o pensar nietzschiano: a vida. E, quando se estabelece a vida como esse valor fundamental a que se ter em mente tudo o que a ela concorre, promovendo-a e afirmando-a. Ora, se a vida, na concepção nietzschiana, é pensada como um conjunto de forças em luta, a que se atentar para tudo o que promove a força. Tudo o que está em movimento é força, portanto, em vias de extravasamento, de irrupção, de externação. Se a expressão externa da força é o que contribui com a vida, então a que atentar para a direção que a força assume: ou se recolhe para dentro, ou se direciona para fora. Apenas por este segundo movimento há uma força capaz de criar e, por essa razão, afirmar a vida. Por essa razão, a direção da força é o aspecto chave para perceber se afirma ou não a vida. E, neste direcionamento a lei que governa o movimento da natureza é de importância fundamental, desde que não a cerceie, mas sim a maximize. Dentro deste paradigma a lei natural não pode ser outra senão a lei compreendida como vontade de potência. A vontade que quer, a todo o instante, se tornar plena, atingindo assim patamares mais potentes.

Os textos de Nietzsche, tanto as obras publicadas como os escritos póstumos e cadernos, refletem a lei natural como uma faca de dois gumes. Ou seja, a lei natural, por ser lei da natureza, pode limitá-la, no sentido de estabelecer interditos em seu movimento expresso mediante forças, ou pode afirmá-la, no sentido de fazer com que este movimento expresso em forças atinja patamares sempre mais culminantes de potência. Para afirmar a vida, a lei deve estar despida da moral, movendo a vontade para o querer assenhorar-se.

A vontade de potência é, portanto, a lei da vida. Pela vontade que quer assenhoramento se dispõe as forças no sentido de as conduzir até a sua expressão mais forte. Esta expressão se alcança quando as forças se dispõem hierarquicamente, em luta por sobreposição de umas sobre as outras. De modo que ao atingir sua maximização se tornam plenas, contudo, uma plenitude que não passa de um instante, mas não qualquer instante, e sim, um instante que se eterniza, pelo seu movimento de vir a ser, em eterno retorno. A lei natural nietzschiana conduz as forças para o seu ponto mais culminante, pelo movimento da vontade que quer retornar eternamente.

\footnotetext{
22 "O termo 'natureza', 'lei natural' está faltando. A psicologia rudimentar de um perpetrador pertence a todos os efeitos: a pessoa é a si mesma apenas causa no caso em que sabe que quis. Consequência: os estados de poder imputam a sensação de não ser a causa, de ser irresponsável por ela: vêm sem serem desejados: consequentemente não somos os autores: a vontade não livre (ou seja, a consciência de uma mudança conosco, sem que o desejemos) uma vontade alheia requer consistência: o homem não ousou atribuir todos os seus momentos fortes e surpreendentes a si mesmo - ele os concebeu como "passivos", "sofridos" como avassaladores: a religião é uma semente uma dúvida sobre a unidade da pessoa, uma alteração da personalidade: na medida em que tudo o que é grande e forte foi conceituado pelo homem como sobre-humano como estranho, o homem encolheu - ele colocou os dois lados, um muito patético e fraco e outro muito forte e surpreendente dividido em duas esferas, a primeira foi denominada 'homem', a segunda 'Deus'." (Nc/FP da primavera de 1888, 14[125], KSA, 13.306-7).
} 
A lei natural, enquanto lei que quer assenhoramento, pela ativação das forças até seu ponto máximo, se coloca ao lado da vida: é ela a lei da vida. Consiste numa lei que, ao governar os movimentos da natureza, aponta para aquilo que na vida respira querer, desejo de mais, de ultrapassamento. Distante, portanto, dos interditos interpostas pela moral que limita e submete a vida aos ditames do ascetismo que degenera. A lei, como vontade de potência, afirma a vida naquilo que a plenifica, a ponto de desejar retornar eternamente, por mais desafiantes que sejam os pesos e obstáculos que se apresentem. Pois, pela lei da natureza que quer mais, a vida se amplia no sentido afirmativo. Os ditames legais da natureza, ao invés de limitar, em doutrinamentos morais, ampliam, em extravasamentos pulsionais. 


\section{Referências}

DOSTOIÉVSKI, Fiódor. Crime e Castigo. Rio de Janeiro: Livraria José Olympio Editora, 1960. ITAPARICA, André Luís Mota. Legislador (Gesetzgeber). In: Dicionácio Nietzsche. São Paulo: Edições Loyola, 2016. PP. 282-283).

JANZ, Curt Paul. Friedrich Nietzsche. Uma biografia. Vol. II: Os dez anos do filósofo livre (Primavera de 1879 a dezembro de 1888). Trad. Markus A. Hediger e Luís M. Sander, Petrópolis: Vozes, 2015.

NIETZSCHE, F. W. Kritische Studienausgabe. Herausgegeben von Giorgio Colli und Mazzino Montinari. Berlin: Verlag de Gruyter, 1999. 15 Bd.

NIETZSCHE, F. W. Sämtliche Briefe: Kritische Gesamtausgabe Briefwechsel KGB.

Herausgegeben von Georgio Colli und Mazzino Montinari. Berlin: Walter de Gruyter, 1986. 8 Bd.

NIETZSCHE, F. W. O nascimento da tragédia. Trad. Paulo César de Souza. São Paulo: Companhia das Letras, 1992.

NIETZSCHE, F. W. Obras incompletas. Trad. Rubens Rodrigues Torres Filho. São Paulo:

Editora Nova Cultural Ltda, 1999.

GIACÓIA JR, Oswaldo. Nietzsche. O humano como memória e promessa. Petrópolis: Vozes, 2013. SALAQUARDA, Jörg. Nietzsche e a tradição judaico-cristã. In: Nietzsche. MAGNUS, Berbard \& HIGgINS, katheleen M. (Org.) Trad. André Oídes. São Paulo: Editora Ideias \& letras, 2017. PP. 115-146.

SCHRIFT, Alan D. O legado francês de Nietzsche. In: Nietzsche. MAGNUS, Berbard \& HIGgINS, katheleen M. (Org.) Trad. André Oídes. São Paulo: Editora Ideias \& letras, 2017. PP. 283-418.

STEGMAIER, Werner. As linhas fundamentais do pensamento de Nietzsche. Trad. Oswaldo Giacóia Jr. Petrópolis: Vozes, 2013.

WOODWARD, Ashley. Nietzscheanismo. Trad. Diego Kosbiau Trevisan. Petrópolis: Vozes, 2016.

Autor(a) para correspondência / Corresponding author: Adilson Felicio Feiler. afeiler@unisinos.br 